\title{
STANCE IN ADVANCED ACADEMIC WRITING BY SAUDI EFL POSTGRADUATES: A CORPUS-BASED STUDY OF CRITIQUE WRITING
}

\author{
Abdulwahid Qasem Al Zumor \\ Applied Linguistics, King Khalid University, Saudi Arabia \\ Corresponding Author Email: aalzomr@kku.edu.sa
}

\begin{tabular}{ll}
\hline \hline Article Info & Abstract \\
\hline Article History & Whether the postgraduate students in the EFL context are adequately trained to \\
Received: September 2021 & express their authorial voice in academic writing in an appropriate tone has not \\
Revised: October 2021 & been clarified enough in the literature. The aim of this study is to explore the \\
Published: October 2021 & linguistic resources used by Saudi postgraduate students of Applied Linguistics \\
\hline Keywords & to construct stance when they write critique essays. To achieve this goal, a corpus \\
EFL writers' Stance; & of 78000 words was built from 73 critique essays collected in five years. To \\
Hedges; & analyze this corpus, LancsBox corpus analysis software was used to generate the \\
Boosters; & concordances with frequencies of key words in context. The model of corpus \\
Attitude Markers; & analysis used was Hyland's (2005) which views stance as a construct within a \\
Self-mentions & model of interaction in academic discourse that comprises boosters, hedges, \\
& attitude markers, and self-mentions. The major findings of the study showed that \\
the most frequently used stance markers were hedges, followed by attitude & markers, then boosters, and finally self-mentions. In addition, the linguistic \\
resources used in these strategies of stance construction by the students in this \\
particular context need to be enhanced in order to conform with conventional \\
standards of academic writing. To meet this ambitious requirement, the study \\
recommends explicit instruction, training, and showcasing these textual \\
resources as they occur in high quality discipline-specific publications.
\end{tabular}

\section{INTRODUCTION}

One of the major goals of teaching composition courses to postgraduate students should be to enable them to become autonomous members of the academic writing community. This ambitious goal entails that academic writing instructors should focus their efforts on training advanced students not only on conventions such as unity, coherence, support and sentence skills but also on building and reflecting a sense of voice and stance in their writing (Escobar \& Fernández, 2017, p. 99). Since the act of writing is inevitably influenced by writer's life histories and experiences, it should not be introduced to postgraduate students as simply the communication of ideas in an impersonal and detached manner but as an activity through which they construct a credible representation of their professional identity with authorial presence (Attarzadeh \& Khansir, 2016; Bahrami et al., 2018; Hyland, 1998; Yoon, 2017). Research can draw on the key resources that novice academic writers in the EFL context possess and propose pedagogical recommendations regarding the gaps that need to be filled and, therefore, potentially contribute to supporting the emerging community of authors.

The objective of the present study is to explore stance-taking strategies as used by postgraduate students of the Master program of Applied Linguistics when they write a critique essay at a Saudi university. In order to achieve this purpose, the present study followed (Hyland, 2005) model of approaching interaction in academic writing with its major components of stance and engagement. Hyland refers to stance as "the way writers present themselves and 
convey their judgements, opinions, and commitment. It is the way that writers intrude to stamp their personal authority onto their arguments or step back and disguise their involvement" (Hyland, 2005, p. 176). It is expressed through expressions of hedges, boosters, attitude markers, and self-mentions. By engagement, Hyland means how "writers relate to their readers with respect to the positions advanced in the text." It comprises the ways writers bring readers into the discourse to anticipate their possible objections. The five main elements of engagement are reader pronouns, personal asides, appeals to shared knowledge, directives, and questions.

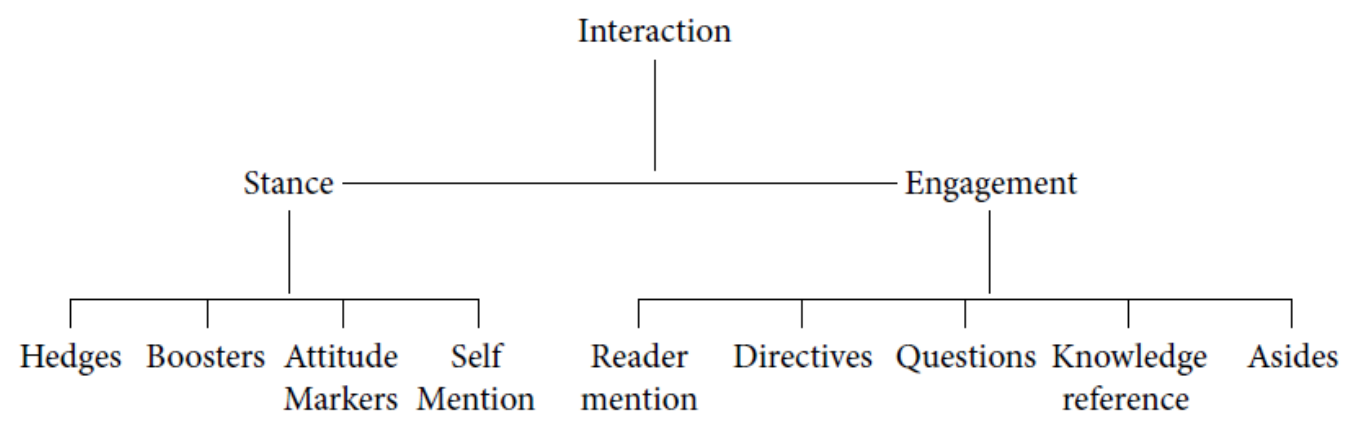

Hyland's (2005) Model

This theoretical framework has attracted the attention of a large number of researchers in the field of academic writing in different language contexts. Google scholar metrics report that it has been cited more than 1700 times and its impact is likely to continue. The present study focuses on stance only because the author aims basically at exploring the linguistic resources used by the emerging Saudi scholars of Applied Linguistics to express their personal views and authorial voice.

\section{Review of Related Studies}

\section{Stance, Voice, Attitude, and Appraisal}

Hood (2010, p. 6) argues that "The assumption that a written report of academic research constitutes an entirely objective representation of empirically derived facts is one that is now unlikely to be made within any discipline or research tradition." This recognition has led to much of analytical research in applied linguistics that aims at the evaluation of written academic discourse. Evaluation in this context can mean taking stance, expressing voice, or appraisal of academic knowledge. Stance and voice are often used interchangeably, though they also overlap. Voice can be considered as community-oriented like disciplinary voice (Hyland, 2008) while stance can refer to the individualized assessment and personal evaluation and commitment by the writer. Both stance and voice can be used to refer to the expression of writer's perspectives, authoritativeness, and presence (Hyland, 2012).

Expressions of evaluative language can also be analyzed with reference to attitude as one of the major components of Appraisal Theory within the theoretical framework of Systemic Functional Linguistics. According to (Wei et al., 2015, p. 235), the Appraisal Theory ( Martin $\&$ White, 2005) attempts to explain how language is used to evaluate, to adopt stances, to construct textual personas, and to manage interpersonal positioning and relationship.

\section{Stance in EFL/ESL Argumentative Texts}

Research in the literature on expressing "stance and voice" in a foreign or second language raises the concern that students in such contexts are rarely taught the features which express interpersonal aspects of language, and academic writing in English is introduced to them as impersonal and faceless (Escobar \& Fernández, 2018, p. 98; Hyland, 2012, p. 137). Other relevant studies emphasize the perspective from which academic writing should be 
approached. Advanced EFL students should understand the purpose of academic writing is not only informative or ideational. It is rather a social act that enhances a writer-reader interaction (Al-Mudhaffari et al., 2020; Hyland, 2012).

Similar findings argue that advanced learners can master the basic rules of syntax and morphology, but encounter the challenge of using rhetorical skills, particularly the construction of writer stance (Chang \& Schleppegrell, 2011; Connor \& Upton, 2016; Al-Mudhaffari et al., 2020) . They also lack awareness of the appropriate degree of directness and indirectness in demonstrating their stance towards the epistemological content of a text. Some studies refer to stance and voice as evaluative language (Martin \& White, 2005) or attitude. For example, Lee (2008) investigated how undergraduate students express evaluative language in high-graded and low-graded persuasive essays. The study revealed that, while high-graded writers maintained their formality, they exploited multiple attitude-invoking judgment strategies in a skillful manner.

This finding might have been caused by the type of subjects who participated in the study. They were a mix of native and non-native English speakers. Some other relevant studies refer to stance strategies as appraisal resources (Alramadan, 2020; J. R. Martin \& White, 2007). Alramadan (2020) investigated the introductions of Applied Linguistics research papers that are written in English and Modern Standard Arabic by: (1) published English-speaking academics, (2) published Saudi academics and (3) Saudi EFL Master's degree students. Results also showed that "the stance construed by the EFL writers did not reflect the exclusive influence of any of the two cultures involved, but represented an inter-genre with a blend of different features coexisting in the same text." This result is expected given the level of writers "Master's degree" and the instructional environment "EFL". Considerable body of research on stance and authorial voice of second and foreign language postgraduate writers has equally emphasized the need for explicit instruction of attitude conventions and rhetorical features of academic writing (Alramadan, 2020; Al-Rubaye, 2015) that includes modelling stance (Cheung, 2017) and voice in contexts of concordances (Yoon \& Römer, 2020).

Research on stance as expressed by advanced EFL writers has not received enough attention. Existing literature shows the focus has been mainly on the expression of stance in the published research of ESL student-writers. Usually, they are required to publish at an advanced stage in their study. The focus of the current study is on the linguistic resources advanced EFL student-writers employ to articulate stance while they are still in the early stages of their preparation process to join authors community. Given the characteristics of academic writing instruction in the EFL setting, it is hypothesized that challenges are more serious. To explore how Saudi postgraduate students of Applied Linguistics construct stance in their persuasive arguments, the current study attempts to answer the following research questions:

1. What are the actual linguistic resources the Saudi postgraduate students of Applied Linguistics use to express stance in their critique writing?

2. What knowledge do the Saudi postgraduate students of Applied Linguistics have about linguistic resources to express stance?

\section{RESEARCH METHOD}

\section{Research Sample}

The author of this research taught advanced academic writing course to the MA Applied Linguistics students at a Saudi university several times since 2015. The average number of MA students who join the Applied Linguistics program annually is 15. Majority of them come from South Saudi Arabia. One of the topics in this course is how to write a critique essay. The students are usually taught the structure of this writing genre. In their second year, they are required to submit a publishable research paper before they graduate. However, they are not explicitly taught how to express authorial stance when they critique the arguments and assumptions of other authors with the exception of little exposure to "self-mention" in critique 
essays. I intentionally ask every new student intake to write a critique essay on a published article that discusses learning barriers in the Saudi context after permission sought from the author. The average number of words of each critique essay submitted by the students is 1068 . Fifty submissions came from female students and twenty-three were written by male students.

\section{Method and Corpus}

The corpus-based approach was used to answer the first research question. The actual linguistic resources used by Saudi postgraduate students to express stance were identified by building a corpus of 73 critique essays which make 78000 words. Corpus approach is empirically based and provides an opportunity to test assumptions about language use against patterns found in naturally occurring discourse and then to review our pedagogical practices accordingly (Biber et al., 1994, p. 171).

To gauge the participants' knowledge about the components of stance in Hyland's model, the tool used was an open-ended questionnaire. The data were collected from a convenience sample of twenty students sampled on the basis of availability. All of them had already submitted critique essays based on the aforementioned published article. The open-ended questions elicited responses about students' knowledge and use of stance markers "boosters, hedges, attitude markers, and self-mentions" in both English "the participants' foreign language" and Arabic "their native language".

\section{Data Analysis}

The data collected from the open-ended questionnaire were analyzed by using thematic analysis. This analysis tool is used to identify patterns within and across data in relation to participants lived experience, views, and perspectives (Clarke \& Braun, 2017, p. 297). To analyze the essays and search for frequency of specific instances of linguistic markers that express stance, LancsBox "Lancaster University corpus toolbox" was used. It is a free corpus analysis software package that supports analysis of word and phrase frequencies and distributions in addition to supporting statistical comparisons (McEnery et al., 2019).

\section{RESEARCH FINDINGS AND DISCUSSION}

The quantitative results generated by LancsBox show the most frequently occurring stance markers as used by the Saudi postgraduate students of Applied Linguistics in their critique essays. The top ten markers of each stance component of Hyland's model were searched and quantified. The most frequently used markers were hedges (878 instances), followed by attitude markers (741), then boosters (650) and finally self-mentions (580). Nivales (2011) believes that the use of hedging in novice writers' articles can be considered as a genuine representation of uncertainty. This finding may not corroborate Hyland \& Milton (1997, p. 835) who found in a study with a corpus of 1,000,000 words that the "non-native speakers of English failed to employ epistemic commitment by representing a more authoritative stance in English." Literature of the use of hedging and boosting by non-native English writers reveals fuzzy findings (Hinkel, 1997).

\section{Hedges}

According to Aull \& Lancaster (2014, p. 160) "Hedging refers to a wide range of linguistic resources for decreasing epistemic commitment and expanding discursive space." Table 1 below presents the statistics of hedges occurrence in the corpus of this study. The first column lists the top ten stance expressions used to express hedging. The second column shows the frequency of occurrence of each hedge marker in the whole corpus. The third column calculates the hedging markers' normalized frequency of occurrence per 10,000 words. The figures in the last column indicate the number of essays in which each stance marker appears. This description of columns applies to all other stance markers. The highest frequency of 
occurrence goes to the lemma "general" and its variants like "generally, generalizing, generalization", while the lowest frequently used hedge word is the modal verb "could".

Table 1

Hedges

\begin{tabular}{|c|c|c|c|}
\hline Hedge Marker & Frequency & Per 10k & Texts: $n=73$ \\
\hline general** & 238 & 30.48 & 61 \\
\hline may/might & 215 & 20 & 68 \\
\hline should & 174 & 22.28 & 58 \\
\hline claim & 69 & 8.84 & 31 \\
\hline assume* & 65 & 8.58 & 27 \\
\hline would & 63 & 8.07 & 33 \\
\hline must & 58 & 7.43 & 25 \\
\hline think & 58 & 7.43 & 31 \\
\hline $\operatorname{argue}^{*}$ & 56 & 7.17 & 31 \\
\hline could & 56 & 7.43 & 35 \\
\hline
\end{tabular}

The data clearly show that most of the linguistic resources used by the participants in their critique essays are modal verbs. They comprise $65 \%$ of the top ten hedge expressions. Modal verbs are the most typical realization of hedges and boosters in English (Orta, 2010). The following examples illustrate how the postgraduate students use modal verbs to express their stance:

(1) However, there are many factors that might form a barrier to the learning process.

(2) This may lead the reader to misunderstand the meaning.

(3) A major problem that should have been considered by Author ...

(4) As a Saudi student, I could easily agree or disagree with some points of this research paper.

(5) In general, the research is not organized.

(6) I think that the use of the word "most" in some of the points without adding statistics is not persuasive.

(7) The researcher argues that the outcomes of English education are unsatisfying due to late exposure to English language.

(8) We obviously assume this is a matter of limitation.

(9) Most of these reasons seem to be reasonable.

(10) I would prefer the usage of the word "challenges".

Such potential in the postgraduate students to hedge even though they were not explicitly taught to do so should be encouraged and refined in order to help them meet the expectations of experienced academic writing community. The examples above indicate the writers are aware of their interactive role with the readers of their critical reviews as well as the authors of the text that is critically appraised.

Although the data analysis reports other instances of hedge markers as shown in table1 to express stance by the student-writers of critique essays in this study, these linguistic resources appear to be limited in scope and the evidence gained from the current corpus illustrates heavy dependence on modal verbs. Explicit training should include the range of various possible resources to express hedging such as evidential verbs, mental process verbs, approximative adverbs and downtoners and minimizers. 


\section{Boosters}

The second highest frequency of linguistic resources to express stance in the current corpus are boosters. They "allow writers to express their certainty in what they say and to mark involvement with the topic and solidarity with their audience (Hyland, 2005, p. 179)." They increase authorial commitment and minimize space for alternative views. Table 2 below shows the top ten booster markers as used by the student-writers in this study.

Table 2

Boosters

\begin{tabular}{c|c|c|c}
\hline Boost Marker & Frequency & Per 10k & Texts: $\boldsymbol{n = 7 3}$ \\
\hline Very & 152 & 19.46 & 51 \\
\hline Without & 83 & 10.63 & 44 \\
\hline Found & 72 & 9.22 & 46 \\
\hline A lot & 72 & 9.22 & 39 \\
\hline Show $*$ & 62 & 7.94 & 39 \\
\hline Accurate & 45 & 5.76 & 30 \\
\hline Strong* & 39 & 4.99 & 25 \\
\hline Clearly & 34 & 4.35 & 19 \\
\hline Believe & 32 & 4.1 & 20 \\
\hline Much & 28 & 3.59 &
\end{tabular}

As Table 2 shows, the intensifier "very" tops the list of boosters followed by other words which may not be listed among the most common boosters that are used by experienced academic writers to express stance. Aull \& Lancaster (2014, p. 162) found that "there is a general trend of more developing academic writers using more boosters and fewer hedges, whereas the opposite is the case with use of hedging, which are used more frequently by the more advanced writers." The results of this study do not corroborate this finding. More hedges were used by the participants although they can be considered as developing academic writers because they are still in the first year of their Master studies.

The only adverb that occurred among the top ten boosters is "clearly". Research on boosters usually refers to a list of predefined adverbs to illustrate the most commonly used boosting resources by experienced academic writers. The list includes really, extremely, completely, absolutely, definitely, certainly, strongly, highly, remarkably, etc. Some of them have occurred in our corpus, yet with very low frequency of occurrence. The following extracts are examples that illustrate boosters in the current corpus.

(1) The author is very persuasive in his writing.

(2) Some information is not fairly interpreted and without evidence to justify the claims.

(3) He [the author] circulates some ideas a lot.

(4) The writer showed views worthy of research.

(5) The information provided in the article is accurate.

(6) The article is strong in its structure and topic.

(7) I think the author clearly conveyed his ideas.

(8) I believe this article does not add much regarding teaching in Saudi Arabia.

(9) In conclusion, this is a much-needed paper with an important message.

(10) Overall, I find this article quite informative. 
The overall findings of the current study are similar to the findings of Serholt (2012) who investigated the overall frequency in which Swedish advanced learners of English use hedges and boosters in their academic writing. The study found that both males and females displayed substantially less use of boosters than hedges.

\section{Attitude Markers}

Both hedges and boosters are used by writers to express epistemic stance. Attitude markers, on the other hand, are used to indicate the writer's affective attitude to propositions conveying surprise, agreement, importance, frustration, rather than commitment (Hyland, 2005, p. 180). Attitude is most explicitly expressed by attitude verbs, affective adverbs, and evaluative adjectives. In the current study, the range of attitude markers used to express stance by the Saudi postgraduate students of Applied Linguistics is broader than the range of those markers used in hedging and boosting. To maintain consistency in data analysis, I have selected the top ten attitude markers as they appeared in the corpus. See Table 3 below.

Table 3

Attitude markers

\begin{tabular}{c|c|c|c}
\hline $\begin{array}{c}\text { Attitude } \\
\text { Marker }\end{array}$ & Frequency & Per 10k & Texts: $\boldsymbol{n = 7 3}$ \\
\hline Important & 168 & 21.51 & 56 \\
\hline Agree & 109 & 13.96 & 53 \\
\hline Only & 96 & 12.29 & 33 \\
\hline Fail & 77 & 9.86 & 35 \\
\hline Good & 72 & 9.22 & 41 \\
\hline Main & 55 & 7.04 & 37 \\
\hline Great & 50 & 6.4 & 27 \\
\hline Disagree & 49 & 6.27 & 36 \\
\hline Significant & 38 & 4.87 & 18 \\
\hline Useful & 24 & 3.07 & 26 \\
\hline
\end{tabular}

The most frequently occurring attitude markers in this study as shown in Table 3 reveal their function. Words like important, agree, good, great, significant, appropriate, and so on are used to assist writers to convey their evaluation and personal attitude towards propositions in the text that was critiqued. They clearly inform the readers about the authors' point of view and their positions towards academic texts. Azar \& Hashim (2019, p. 166) classified the types of attitude markers into four: linguistic resources that express significance, limitations and gaps, emotion, and assessment. The following examples from the corpus illustrate how attitude markers are used in critique writing context by postgraduate EFL students.

(1) Dr. Author's article shows very important facts regarding language learning in Saudi Arabia.

(2) I do agree to a certain extent with him on the difficulties that Saudi students face.

(3) He depended only on his experience of teaching.

(4) Dr. Author fails to show evidence to support his claim.

(5) Overall, this article is good.

(6) This is the main idea of the author's article.

(7) Dr. Author has made a great effort to figure out the obstacles which prevent Saudi students from learning. 
(8) As a Saudi student, I could easily agree or disagree with some points of this research paper.

(9) The information shown in the article is significant and cover almost all aspects causing learning barriers in the Saudi society.

(10) This article is very useful.

Among the top ten attitude markers, seven are adjectives. This observation indicates that the range of attitude markers used by the participants in the current corpus is not expansive. Very few verbs and adverbs are used to express the student-authors attitude towards the propositional content of text. This weakness might be attributed to writing in a foreign language setting as well as lack of explicit instruction of the different types of linguistic resources that can be used to express authorial stance. Blagojević (2009, p. 65) classified attitude markers into six categories that include adverbs, adverbial phrases, verbs, adjectives, modal verbs, and nouns of specific semantic content. Any explicit training on stance markers should take these categories into consideration.

\section{Self-Mention}

The last component of Hyland's model of stance analysis is self-mentions. This strategy refers to the use of first person pronouns and possessive adjectives to introduce propositional, affective, or interpersonal information (Hyland, 2005). They play a significant role in communicating with the audiences and constructing authorial identity. In the present corpus, the writers used these linguistic markers frequently as demonstrated in Table 4 below.

Table 4

Self-mention

\begin{tabular}{c|c|c|c}
\hline $\boldsymbol{I}^{\text {st }}$ Person Pronoun & Frequency & Per $10 \boldsymbol{k}$ & Texts: $\boldsymbol{n = 7 3}$ \\
\hline$I$ & 380 & 48.66 & 65 \\
\hline$w e$ & 101 & 12.93 & 37 \\
\hline$m y$ & 61 & 7.81 & 31 \\
\hline Our & 25 & 3.2 & 16 \\
\hline$m e$ & 13 & 1.66 & 10 \\
\hline
\end{tabular}

The following excerpts illustrate how Saudi postgraduate students of Applied Linguistics utilize self-mention to articulate their voice and communicate their stance.

(1) I will begin to critique this article by objectively summarizing the text.

(2) Based on my careful reading of the author's research paper, I believe that the given information is not up to date.

(3) We cannot say that the author argued logically.

(4) We cannot say that most of the adult learners in Saudi Arabia have no childcare responsibilities.

(5) In my point of view, I believe that one of the huge weaknesses in the article is that the researcher was biased.

(6) My feedback and reaction is positive toward the author's ideas and I support them.

(7) Barriers that act like obstacles on the way of learning are very common and can be seen in our day-to-day teaching activities.

(8) I agree with this point because we see these difficulties in our daily lives whether in school or in street.

(9) The title of the research attracted me but I experienced difficulties while working on this research specifically when I was trying to find out the thesis statement.

(10) This made me think about the reasons, and I believe it will be a great contribution if any scholar investigated this field. 
The examples 31 to 40 demonstrate clearly that the academic writers in this study have instilled their voice into their claims, positions, and interactions with the text and their audience. Although they expressed their views against using self-mention in academic writing as will be shown below, the use of self-mention strategy 580 times implies that even novice writers can reflect their identity as insiders (Alharbi, 2020) and are aware of the importance of protecting themselves in their texts and that "[a]cademic writing is not just about conveying an ideational content, it is also about the representation of self" (Hyland \& Nelson, 2002, p. 1091; Yazılarda et al., 2017).

We may infer from the above self-mention examples that the first-person pronouns and possessive adjectives in their singular and plural forms have relatively different functions in this corpus. The first person singular pronoun "I", the possessive adjective "my" and the object pronoun "me" straightforwardly articulate the writer's epistemic and attitudinal stance towards other authors" propositions, whereas, the first person plural pronoun "we" and the possessive adjective "our" as demonstrated in instances 33, 34, and 37 are reader-oriented and perform the function of bringing the reader to the discussion for persuasive purposes in order to construct a writer-reader dialogue (Hyland, 2001).

\section{Problems in Presenting Authorial Stance}

Although some student-writers in this study demonstrated their ability to articulate stance through boosters, hedges, attitude markers and self-mentions, substantial instances of stanceexpressing statements seemed to be problematic in the sense that they may deviate from the conventions of expressing authorial stance in the academic writing community. To confirm this potential divergence this divergence, Bahrami et al. (2018, p. 70) noted that "in soft disciplines, [like applied linguistics], novice writers often fail to keep a fine balance between being humble (i.e., acknowledging others ${ }^{\text {ee }}$ perspectives) and authoritative (i.e., expressing [their] own interpretations and points of view directly) and this has led to failure in publication in many cases." Below are selective examples of such problematic usages as they occurred in the present study's corpus.

(11) Another fallacy is when the writer said that Saudi students practice English only in classes which is a hasty generalization.

(12) The writer did not succeed in covering all the barriers. He only discussed some problems from his point of view.

(13) I completely disagree with the author because as a Saudi English student at KKU I had four courses concerned with listening and speaking.

(14) I strongly disagree with the false connection between the family's poor educational background, salaries, and children's weak educational progress.

(15) I do not trust the accuracy of the information that he has mentioned about Saudi community.

The use of phrases like "fallacy, hasty generalization, completely disagree, accuracy of the information" seem to be a result of transfer of training as such expressions are found in the course textbook. In the Advanced Academic Writing course, the postgraduate students of Applied Linguistics are taught a topic on critique writing and such phrases introduced to them in the context of how to do critical reading and what they should appraise. Unfortunately, they are not taught how authorial stance should be articulated constructively. The consequence is that viewing oneself as an author like in the task given to the postgraduate student students in this research might have led them to be authoritative and therefore to feel they have the right to project their subjectivity into the text (Bahrami et al., 2018). Due to inadequate linguistic knowledge, novice writers may "select a strategy which they believe conveys a socially appropriate illocution but which actually carries an inappropriate degree of directness, 
deference, or assertiveness for an academic register" (Hyland \& Milton, 1997, p. 193). The same concern applies to the following examples from the corpus.

(16) His interpretation of information also is clearly affected by his negative image of Saudi people.

(17) He must have done a survey or a study before he made this accusation.

(18) But when he mentioned the barriers of learning in Saudi Arabia, he didn't use any appropriate methods to provide evidence.

(19) Therefore, according to the previous sources, many of Author's claims were not fair or accurate and [were] devoid of logic.

(20) I find this work as weak and unworthy because of the absence of sources and also because of the hasty generalizations that Author made which reduces its value.

(21) Author fails to provide logical reasoning for some issues.

(22) The analysis of the learning barriers in this article lacks credibility and statistical evidence.

(23) He doesn't mention any reliable source of information concerning the abovementioned barriers.

The above examples vary in the types of criticism. Some stance statements target the author and his credibility and objectivity; others evaluate the article's methodology, analysis, cited sources, and the logic of argumentation.

(24) I would not recommend this work to anyone because it is not written properly, and it based most of its argument on false information or unproven claims.

This style of critique writing as illustrated in the last example or the previous one confirms the findings of Hyland \& Milton (1997, p. 193) that the academic writing of many L2 learners is characterized by firm assertions, authoritative tone, and strong writer commitments when compared with the academic discourse of native speakers. To address this problem, ESL/EFL academic writing instruction should include explicit teaching of how to write effective pragmatic argument to help students establish a balance between hedging and toning down the claims and being polite, respectful, and constructive (Uysal, 2012, p. 150).

\section{Knowledge about L1 and FL Writing}

This section reports the results of an open-ended questionnaire that asked twenty of the participants in this study about the knowledge they possess about stance markers in both their L1 (Arabic) and their FL (English). The goal was to explore the potential impact of this type of knowledge on the postgraduate students' linguistic choices while constructing their stance in the critique essay writing. Bahrami et al. (2018) argue that although explicit knowledge of conventions and rules is necessary for writing, it cannot be enough for writing effectively and coherently,.

The first question in the survey was framed as follows: "Boosters" in academic writing refer to the use of linguistic devices to express authors' certainty and confidence in relation to the information they present. Do you use them? Give examples. Do we have boosters in Arabic academic writing? Give examples." The answers provided to these questions revealed that students' knowledge about boosters in English and Arabic seems to quite blurred.

(1) I am not experienced in Arabic academic writing, but I am certain that there are boosters.

(2) Sometimes I use them when I'm sure of the given information.

(3) When it comes to Arabic, I honestly have no background, but I think the same is happening with Arabic

(4) I don't know about Arabic, but I think we have.

(5) I do not have any idea about boosters! 
(6) I don't know if we have a particular term to describe them in Arabic

(7) Yes, we do have boosters in Arabic.

Moreover, these replies imply that the participants' knowledge about boosting in their Arabic L1 is inadequate. Arab students of English and applied linguistics are not required to do academic writing tasks in Arabic and topics like stance are not taught in their school education. Only eight of the twenty respondents provided examples of both Arabic and English boosters. A similar question was asked about hedging knowledge. Fourteen respondents stated that they know hedges and use them; twelve of them provided examples from both English and Arabic; four students replied that they do not know about hedges. The following three examples illustrate the students' responses:

(8) I do use them, because I believe it shows respect to the audience who may be knowledgeable and more sophisticated than me.

(9) I think in argumentative writing authors should avoid hedges.

(10) To be honest, I am lacking in many skills of writing.

(11) Yes, I use hedges in both English and Arabic academic writing such as "possibly, seems, looks like and it might be."

The interpretation of why hedges were used more than any other stance markers can be attributed to the respondent's tacit knowledge about the importance of hedging by novice writers. The third question in the open-ended questionnaire elicited responses regarding postgraduate students' knowledge of attitude markers. Fifteen respondents replied positively that they know attitude markers and use them. One of them wrote, "I don't know about Arabic academic writing." Five students stated that they don't know about attitude markers.

(12) I use them. Unfortunately, x claims, argues...etc. I don't know about Arabic academic writing.

(13) I use a lot of attitude markers in my writing to express different attitudes.

(14) Yes, I use them in English Academic writing and we have attitude markers in Arabic like "as well as, as a result, and consequently.

(15) I do not know about attitude markers.

In example (14), although the respondent affirmed his/her knowledge and use of attitude markers, the two illustrative examples do not belong to this category. The last question in the survey inquired about "self-mention" as follows: What do you think of using "first person pronouns" or "self-mention" such as "I" or "we" in academic writing? Do you think this is professional in Arabic academic discourse? Is it fine to use them in English academic writing? Fifteen of the respondents consider "self-mention" to be against the appropriate academic conventions and practices. This finding agrees with Hyland \& Nelson (2002) remark that pledging one's personal opinion in your results with a first person commitment is a risky strategy, and often novice writers lack the confidence to take.

Although the majority of the respondents to the open-ended questionnaire are against using "self-mention", it was found to be used quite considerably when they had to write their critique essays where they were mandated to articulate their voice and express their stance. This was probably a result of the explicit exposure to this strategy in the sample critique essays. 


\section{CONCLUSION}

The present study has attempted to explore how Saudi postgraduate students of Applied Linguistics articulate stance when they critique a published article. The contribution of this research lies in investigating stance taking strategies by postgraduate English users in a foreign language context. Much of the previous research on stance of novice academic writers has been conducted in an ESL context and the examined genre in such setting is usually published or non-published research. The conclusion this study has reached is that Saudi postgraduate students use the four components of stance, namely hedges, boosters, attitude markers, and self-mention although they are not explicitly trained on such strategies. The study has proven that the selected linguistic resources to express stance by the participants require to be enhanced in order to conform with and emulate the conventions of stance articulation by expert academic writers. Assisting our emerging scholars to achieve this ambitious goal necessitates taking practical actions by postgraduate programs planners, developers, and course instructors. Some feasible recommendations include explicit instruction in authorial stance-taking in academic writing syllabuses, explicit introduction of social engagement aspects of academic writing, explicit training on textual resources student writers need to express epistemic stance, raising novice writers' degree of noticing while critically reading papers written by expert authors to help them internalize review genre conventions, and systematic feedback by instructors on the appropriateness of students' stance-expressing resources.

\section{REFERENCES}

Al-Mudhaffari, M., Hussin, S., \& HoAbdullah, I. (2020). Interactional strategies in L2 writing: An exploration of hedging and boosting strategies in applied linguistics research articles. International Journal of Arabic-English Studies, 20(1), 171-186. https://doi.org/10.33806/ijaes2000.20.1.9

Alharbi, M. (2020). Reimagining the ever-changing construct of Saudi writerly identity: A heuristic approach. Arab World English Journal, 11(4), 254-271. https://doi.org/10.24093/awej/vol11no4.17

Alramadan, M. M. (2020). Authorial stance in English, Arabic and EFL applied linguistics research: An appraisal study. Asiatic, 14(1), 189-216.

Attarzadeh, S., \& Khansir, A. A. (2016). Authorial identity presence: The case of health sciences and life sciences. Modern Journal of Language Teaching Methods, 6(3), 89.

Aull, L. L., \& Lancaster, Z. (2014). Linguistic Markers of Stance in Early and Advanced Academic Writing: A Corpus-based Comparison. In Written Communication (Vol. 31, Issue 2). https://doi.org/10.1177/0741088314527055

Azar, A. S., \& Hashim, A. (2019). The impact of attitude markers on enhancing evaluation in the review article genre. GEMA Online Journal of Language Studies, 19(1), 153-173. https://doi.org/10.17576/gema-2019-1901-09

Bahrami, L., Dowlatabadi, H., Yazdani, H., \& Amerian, M. (2018). Authorial Stance in Academic Writing: Issues and Implications for Research in English Language Teaching. International Journal of English Language \& Translation Studies, 6(2), 69-80.

Biber, D., Conrad, S., \& Reppen, R. (1994). Corpus-based approaches to issues in applied linguistics. Applied Linguistics, 15(2), 169-189. https://doi.org/10.1093/applin/15.2.169

Blagojević, S. (2009). Expressing Attitudes in Academic Research Articles Written By English and Serbian Authors. Linguistics and Literature, 7(1), 63-73.

Chang, P., \& Schleppegrell, M. (2011). Taking an effective authorial stance in academic writing: Making the linguistic resources explicit for L2 writers in the social sciences. Journal of English for Academic Purposes, 10(3), 140-151. https://doi.org/10.1016/j.jeap.2011.05.005 
Cheung, L. (2017). Development of Evaluative Stance and Voice in Postgraduate Academic Writing. 1-122.

Clarke, V., \& Braun, V. (2017). Thematic analysis. Journal of Positive Psychology, 12(3), 297298. https://doi.org/10.1080/17439760.2016.1262613

Connor, U., \& Upton, T. A. (2016). Formulating Writer Stance: A Contrastive Study of EFL Learner Corpora. Applied Corpus Linguistics, 73-89. https://doi.org/10.1163/9789004333772_006.

Escobar, C. C. F., \& Fernández, L. C. (2017). EFL learners' development of voice in academic writing: Lexical bundles, boosters/hedges and stance-taking strategies. GIST-Education and Learning Research Journal, (15), 96-124. https://doi.org/10.26817/16925777.392.

Hamdi Kareem Al-Rubaye, M., \& Hamdi Kareem, M. (2015). BearWorks BearWorks MSU Graduate Theses Metadiscourse in the Academic Writing of EFL and ESL ArabicMetadiscourse in the Academic Writing of EFL and ESL Arabic-Speaking Iraqi Graduate Students Speaking Iraqi Graduate Students "Metadiscourse in the Academi. https://bearworks.missouristate.edu/theseshttps://bearworks.missouristate.edu/theses/17

Hinkel, E. (1997). Indirectness in L1 and L2 academic writing. Journal of Pragmatics. https://doi.org/10.1016/s0378-2166(96)00040-9

Hood, S. (2010). Appraising research: Evaluation in academic writing. Appraising Research: Evaluation in Academic Writing, 1-227. https://doi.org/10.1057/9780230274662

Hyland, K. (2005). Stance and engagement: A model of interaction in academic discourse. Discourse Studies, 7(2), 173-192. https://doi.org/10.1177/1461445605050365

Hyland, K. (2008). Disciplinary voices. English Text Construction, 1(1), 5-22. https://doi.org/10.1075/etc.1.1.03hyl

Hyland, K. (2012). Undergraduate Understandings: Stance and Voice in Final Year. In K. Hyland \& C. S. Guinda (Eds.), Stance and Voice in Written Academic Genres (pp. 134150). Palgrave macmillan. https://doi.org/10.1057/9781137030825

Hyland, K. (2001). Bringing in the Reader. Written Communication, 18(4), 549-574. https://doi.org/10.1177/0741088301018004005

Hyland, K., \& Milton, J. (1997). Qualification and Certainty in L1 and L2 Students' Writing. Journal of Second Language Writing, 6(2), 183-205. https://doi.org/10.1016/S10603743(97)90033-3

Hyland, K., \& Nelson, M. E. (2002). Authority and invisibility: authorial identity in academic writing Cite this paper Related papers Discursive Const ruct ion of Aut horial Voice in English Book Reviews: A Cont rast ive Analysis Authority and invisibility: authorial identity in academic wr. www.elsevier.com/locate/pragma

Lee, S. (2008). Attitude in undergraduate persuasive essays. Prospect: An Australian Journal of TESOL, 23(3), 43-58.

Martin, J. R., \& White, P. R. R. (2007). The Language of Evaluation: Appraisal in English. The Language of Evaluation: Appraisal in English, 1-278. https://doi.org/10.1057/9780230511910

Martin, James R, \& White, P. R. R. (2005). The Language of Evaluation: The Appraisal Framework. Lecture Notes in Computer Science, 256.

Mcenery, T., Brezina, V., Gablasova, D., \& Banerjee, J. (2019). Corpus Linguistics, Learner Corpora, and SLA: Employing Technology to Analyze Language Use. Annual Review of Applied Linguistics, 39(2019), 74-92. https://doi.org/10.1017/S0267190519000096

Nivales, M. L. M. (2011). Hedging in College Research Papers: Implications for Language Instruction. Asian EFL Journal, 52(May), 35-46.

Orta, I. V. (2010). A contrastive analysis of the use of modal verbs in the expression of epistemic stance in business management research articles in English and Spanish. Ibérica, 19(1), 77-96. 
Serholt, S. (2012). Hedges and Boosters in Academic Writing A Study of Gender Differences in Essays Written by Swedish Advanced Learners of English. Linguistic C-essay in English at advanced undergraduate level for general purpose course (EN1C03) Title: Hedges and Boosters $i$.

Uysal, H. H. (2012). Argumentation across 11 and 12 writing: Exploring cultural influences and transfer issues. Vigo International Journal of Applied Linguistics, 9(1), 133-159.

Wei, Y., Wherrity, M., \& Zhang, Y. (2015). An Analysis of Current Research on the Appraisal Theory. Linguistics and Literature Studies, 3(5), 235-239. https://doi.org/10.13189/1ls.2015.030506

Yazılarda, A., İşaret, Y., Kullanımı, E. S., \& Kafes, H. (2017). International Journal of Language Academy THE USE OF AUTHORIAL SELF-MENTION WORDS IN ACADEMIC WRITING. 5, 165-180. http://dx.doi.org/10.18033/ijla.3532

Yoon, H. J., \& Römer, U. (2020). Quantifying Disciplinary Voices: An Automated Approach to Interactional Metadiscourse in Successful Student Writing. In Written Communication (Vol. 37, Issue 2). https://doi.org/10.1177/0741088319898672 